for the outcome due to presence of a bridged syndesmophyte at baseline were excluded. Multilevel generalized estimated equations were used, with separate models per MRI pattern, accounting for correlations within patients and between IdCT readers.

Table 1. Effect of vertebral corner inflammation and vertebral corner fat deposition on syndesmophyte formation

\begin{tabular}{|c|c|c|}
\hline Patterns of lesions over time on MRI & $\begin{array}{l}\text { Corners with VCl/ } \\
\text { VCFD pattern } \mathrm{N}(\%)\end{array}$ & OR $(95 \% \mathrm{Cl})$ \\
\hline 1. $\mathrm{VCl}$ at any $\mathrm{TP}$, irrespective of VCFD & $691(15.0 \%)$ & $2.37(1.49-3.78)$ \\
\hline 2. VCFD at any TP, irrespective of $\mathrm{VCl}$ & $1080(23.5 \%)$ & $2.58(1.97-3.39)$ \\
\hline 3. $\mathrm{VCl}$ on $\geq 1 \mathrm{TP}$ and absence of VCFD on all TPS & $372(8.1 \%)$ & $1.90(1.15-3.13)$ \\
\hline 4. VCFD on $\geq 1 \mathrm{TP}$ and absence of $\mathrm{VCl}$ on all TPs & $754(16.4 \%)$ & $1.87(1.41-2.48)$ \\
\hline 5. VCI precedes VCFD & $43(0.9 \%)$ & $2.20(0.83-5.86)$ \\
\hline $\begin{array}{l}\text { 6. } \mathrm{VCl} \text { precedes or coincides with VCFD. VCFD does } \\
\text { not precede } \mathrm{VCl}\end{array}$ & $198(4.3 \%)$ & $2.33(1.47-3.69)$ \\
\hline 7. Absence of $\mathrm{VCl}$ and VCFD on all TPs & $3108(67.6 \%)$ & $0.35(0.25-0.49)$ \\
\hline
\end{tabular}

$\mathrm{VCl}$, vertebral corner inflammation; VCFD, vertebral corner fat deposition; TP, timepoint.

Results: 50 patients were included, contributing a total of 4600 vertebral corners. Their mean age was 49.3 years (SD 9.8), $86 \%$ were male and $78 \%$ were HLA-B27+. Presence of VCI and VCFD patterns ranged from $43(0.9 \%)$ to 3108 $(67.6 \%)$ corners (Table), with the lowest frequency being for $\mathrm{VCI}$ preceding VCFD. Protection against syndesmophyte development was seen in case of absence of both $\mathrm{VCl}$ and VCFD (OR 0.35) and positive associations with ORs ranging from 1.87-2.58 were observed for various VCI/VCFD patterns. Nevertheless, out of all corners with a new or grown syndesmophyte, $47.3 \%$ of corners according to reader 1 and $43.9 \%$ according to reader 2 had neither VCI nor VCFD preceding the bone formation.

Conclusion: Presence of VCI or VCFD and combinations of the two, measured yearly on MRI, increased odds of bone formation 2 years later, whereas absence of both $\mathrm{VCl}$ and VCFD decreased the odds, showing that $\mathrm{VCI}$ and VCFD have some role in the development of syndesmophytes. However, almost half of all bone formation occurred in corners without VCI or VCFD, suggesting the presence of these lesions in yearly MRIs does not fully explain the development of syndesmophytes. This study confirmed that there is an association between $\mathrm{VCl}$ and VCFD and bone formation also for the thoracic spine and on IdCT compared to conventional radiography.

REFERENCES:

[1] Machado et al ARD 2016

Disclosure of Interests: Rosalinde Stal: None declared, Xenofon Baraliakos: None declared, Alexandre Sepriano: None declared, Floris A. van Gaalen Grant/ research support from: Novartis, Sofia Ramiro: None declared, Rosaline van den Berg: None declared, Monique Reijnierse: None declared, Juergen Braun: None declared, Robert B.M. Landewé: None declared, Désirée van der Heijde: None declared

DOI: 10.1136/annrheumdis-2021-eular.1337

\section{OP0251 DATA-DRIVEN DEFINITIONS BASED ON INFLAMMATORY LESIONS FOR A POSITIVE MRI OF THE SPINE CONSISTENT WITH AXIAL SPONDYLOARTHRITIS}

W. P. Maksymowych ${ }^{1,2}$, R. G. Lambert ${ }^{3}$, X. Baraliakos ${ }^{4}$, S. Juhl Pedersen ${ }^{5,6}$ U. Weber ${ }^{7}$, I. Eshed ${ }^{8}$, P. Machado ${ }^{9}$, M. De Hooge ${ }^{10}$, J. Sieper ${ }^{11}$, S. Wichuk', D. Poddubnyy ${ }^{11}$, M. Rudwaleit ${ }^{12}$, D. Van der Heijde ${ }^{13}$, R. B. M. Landewé ${ }^{14}$, M. Østergaard ${ }^{5,6}$, on behalf of ASAS MRImagine. ${ }^{1}$ University of Alberta, Medicine, Edmonton, Canada; ${ }^{2}$ CARE Arthritis, Rheumatology, Edmonton, Canada; ${ }^{3}$ University of Alberta, Radiology and Diagnostic Imaging, Edmonton, Canada; ${ }^{4}$ Rheumazentrum Ruhrgebiet, Rheumatology, Herne, Germany; ${ }^{5}$ COPECARE, Rheumatology, Copenhagen, Denmark; ${ }^{6}$ Rigshospitalet, Rheumatology, Glostrup, Denmark; ${ }^{7}$ Practice Buchsbaum, Rheumatology, Schaffhausen, Switzerland; ${ }^{8}$ Sheba Medical Center, Radiology and Diagnostic Imaging, Tel Aviv, Israel; ${ }^{9}$ University College London, Rheumatology, London, United Kingdom; ${ }^{10}$ Ghent University Hospital, Rheumatology, Ghent, Belgium; ${ }^{11}$ Charité Universitätsmedizin, Rheumatology, Berlin, Germany; ${ }^{12}$ Klinikum Bielefeld, Rheumatology, Bielefeld, Germany; ${ }^{13}$ Leiden University Medical Centre, Rheumatology, Leiden, Netherlands; ${ }^{14}$ Academic Medical Center, Rheumatology, Amsterdam, Netherlands

Background: The ASAS definition of a positive MRI for inflammation in the spine (ASAS-MRIspine+) is intended for classification of patients as having axSpA but is often misused for diagnostic purposes. This is problematic because bone marrow edema (BME) in the spine may occur in $20-40 \%$ of those with mechanical back disorders. The ASAS MRI group has generated updated consensus lesion definitions which have been validated on MRI spine images from the ASAS Classification Cohort.
Objectives: We aimed to identify quantitative cut-offs based on numbers of vertebral corners that define ASAS-MRIspine+, there being two gold standards: A majority central reader decision as to the presence of spine MRI findings consistent with axSpA B. rheumatologist expert opinion diagnosis of axSpA.

Methods: Eight ASAS-MRI readers recorded MRI lesions in the spine according to recently updated ASAS definitions from 62 cases in an eCRF that comprises global assessment (MRI consistent with axSpA? (yes/no)), and detailed scoring of lesions for all sites in the spine. We calculated sensitivity and specificity for numbers of vertebral corners with BME where a majority of readers $(\geq 5 / 8)$ agreed as to the presence of MRI findings consistent with axSpA. We selected cut-offs with $\geq 95 \%$ specificity. These cut-offs were analyzed for their predictive utility for rheumatologist diagnosis of axSpA by calculating positive and negative predictive values (PPV, NPV) and selecting cut-offs with PPV $\geq 95 \%$. Both criteria were considered requirements for designation of MRI cut-offs defining ASAS-MRIspine+.

Results: MRI findings consistent with axSpA were observed by majority read in $8(20 \%)$ of 40 cases diagnosed with axSpA, and $0(0 \%)$ of 19 cases withou axSpA. Cut-offs achieving specificity of $\geq 95 \%$ for MRI findings consistent with axSpA were 4 vertebral corners (sensitivity $75 \%$ ) for all cases, 3 vertebral corners (sensitivity $37.5 \%$ ) for cases with $\geq 1$ additional location with inflammation, 1 vertebral corner (sensitivity $62.5 \%$ ) in cases with $\geq 2$ vertebral corner fat lesions (Table 1). All of the above cut-offs also had very high PPV ( $\geq 95 \%)$ for diagnosis of axSpA in cases diagnosed by the rheumatologist (Table 2).

Table 1. Majority readers agree MRI findings consistent with axSpA are present is the gold-standard external reference

\begin{tabular}{|c|c|c|}
\hline MRI cut-offs & Sensitivity $(95 \% \mathrm{Cl})$ & Specificity $(95 \% \mathrm{Cl})$ \\
\hline$B M E$ in $\geq 2$ vertebral corners & $87.5(47.3-99.7)$ & $87.0(75.1-94.6)$ \\
\hline BME in $\geq 3$ vertebral corners & $87.5(47.3$ - 99.7) & $94.4(84.6-98.8)$ \\
\hline BME in $\geq 4$ vertebral corners & $75.0(34.9-96.8)$ & $98.2(90.1-100.0)$ \\
\hline \multicolumn{3}{|c|}{ Cases with $\geq 1$ additional non-corner site inflammatory lesion } \\
\hline BME in $\geq 2$ vertebral corners & $37.5(8.5-75.5)$ & $94.4(84.6-98.8)$ \\
\hline BME in $\geq 3$ vertebral corners & $37.5(8.5-75.5)$ & $98.2(90.1-100.0)$ \\
\hline \multicolumn{3}{|c|}{ Cases with $\geq 2$ vertebral corner fat lesions } \\
\hline BME in $\geq 1$ vertebral corner & $62.5(24.5-91.5)$ & $100.0(93.4-100.0)$ \\
\hline BME in $\geq 2$ vertebral corners & $62.5(24.5-91.5)$ & $100.0(93.4-100.0)$ \\
\hline
\end{tabular}

Table 2. Predictive values of cut-offs for number of vertebral corners with BME according to the diagnostic ascertainment of the rheumatologist

\begin{tabular}{|c|c|c|c|c|}
\hline MRI cut-offs & $\begin{array}{l}\text { Sensitivity } \\
(95 \% \mathrm{Cl})\end{array}$ & $\begin{array}{l}\text { Specificity } \\
(95 \% \mathrm{Cl})\end{array}$ & PPV & NPV \\
\hline $\begin{array}{l}\text { MRI findings consistent with } \\
\text { axSpA } \geq \text { any } 2 \text { readers }\end{array}$ & $\begin{array}{c}52.5 \\
(36.1-68.5)\end{array}$ & $\begin{array}{c}94.7 \\
(74.0-99.9)\end{array}$ & $\begin{array}{c}95.5 \\
(75.3-99.3)\end{array}$ & $\begin{array}{c}48.6 \\
(40.2-57.2)\end{array}$ \\
\hline $\begin{array}{l}\text { MRI findings consistent with } \\
\text { axSpA } \geq \text { majority read }\end{array}$ & $20.0(9.1-35.6)$ & $\begin{array}{c}100.0(82.4 \\
-100.0)\end{array}$ & 100.0 & $\begin{array}{c}37.3 \\
(33.7-40.9)\end{array}$ \\
\hline BME in $\geq 4$ vertebral corners & $17.5(7.3-32.8$ & $\begin{array}{c}100.0 \\
(82.4-100.0)\end{array}$ & 100.0 & $\begin{array}{c}36.5 \\
(33.3-39.9)\end{array}$ \\
\hline \multicolumn{5}{|c|}{ Cases with $\geq 1$ additional inflammatory lesion } \\
\hline BME in $\geq 3$ vertebral corners & $10.00(2.8-23.7)$ & $\begin{array}{c}100.00 \\
(82.4-100.0)\end{array}$ & 100.0 & $\begin{array}{c}34.5 \\
(32.2-36.9)\end{array}$ \\
\hline \multicolumn{5}{|c|}{ Cases with $\geq 2$ vertebral corner fat lesions } \\
\hline$B M E$ in $\geq 1$ vertebral corner & $12.50(4.2$ - 26.8) & $\begin{array}{c}100.00 \\
(82.4-100.0)\end{array}$ & 100.0 & $\begin{array}{c}35.2 \\
(32.6-37.9)\end{array}$ \\
\hline
\end{tabular}

Conclusion: A cut-off of BME in $\geq 4$ vertebral corners, or $\geq 3$ corners in the setting of additional inflammatory lesions at other locations or corner fat, are primary candidates for defining ASAS-MRIspine+. These cut-offs apply to typical patients referred to a rheumatologist with a high index of suspicion of axSpA and may not be appropriate in other populations.

Disclosure of Interests: None declared

DOI: 10.1136/annrheumdis-2021-eular.3914

\section{OP0252 ARTHRITIS AND ENTHESITIS IN THE HIP AND PELVIS REGION IN SPONDYLOARTHRITIS - VALIDATION OF} TWO WHOLE-BODY MRI METHODS

M. Wetterslev ${ }^{1,2}$, R. G. Lambert ${ }^{3,4}$, W. P. Maksymowych ${ }^{5,6}$, I. Eshed ${ }^{7}$, S. Juhl Pedersen $^{1}$, P. Bird ${ }^{8}$, M. Stoenoiu ${ }^{9}$, S. Krabbe ${ }^{1}$, A. J. Mathew ${ }^{1,2}$, V. Foltz ${ }^{10}$, F. Gandjbakhch ${ }^{10}$, J. Paschke ${ }^{6}$, G. De Marco ${ }^{11,12}$, H. Marzo-Ortega ${ }^{11,12}$, P. Carron ${ }^{13,14}$, A. E. F. Poulsen ${ }^{1}$, J. L. Jaremko ${ }^{3}$, P. G. Conaghan ${ }^{11,12}$, M. Østergaard ${ }^{1,2}$ on behalf of the OMERACT MRI in Arthritis Working Group. ${ }^{1}$ Rigshospitalet, Copenhagen Center for Arthritis Research, Center for Rheumatology and Spine Diseases, Copenahgen, Denmark; ${ }^{2}$ University of Copenhagen, Department of Clinical Medicine, Copenhagen, Denmark; ${ }^{3}$ University of Alberta, Department of Radiology and Diagnostic Imaging, 
Table 1. MRI-WIPE hip/pelvis and HIMRISS interreader reliability for OMERACT exercises 3-4

\begin{tabular}{|c|c|c|c|c|c|c|c|c|c|c|}
\hline \multirow[b]{3}{*}{ Variables } & \multirow[b]{3}{*}{$\begin{array}{l}\text { No. patients } \\
\text { (cases) }\end{array}$} & \multirow[b]{3}{*}{ Type of score } & \multicolumn{4}{|c|}{ MRI-WIPE hip/pelvis } & \multicolumn{4}{|c|}{ HIMRISS } \\
\hline & & & \multicolumn{2}{|c|}{ Osteitis } & \multicolumn{2}{|c|}{ Synovitis/effusion } & \multicolumn{2}{|c|}{ Osteitis } & \multicolumn{2}{|c|}{ Synovitis/effusion } \\
\hline & & & $\begin{array}{l}\text { Mean } \\
\text { score }\end{array}$ & ICC & $\begin{array}{l}\text { Mean } \\
\text { score }\end{array}$ & ICC & $\begin{array}{l}\text { Mean } \\
\text { score }\end{array}$ & ICC & $\begin{array}{l}\text { Mean } \\
\text { score }\end{array}$ & ICC \\
\hline \multirow{2}{*}{$\begin{array}{l}\text { Exercise } 3 \\
9 \text { readers }\end{array}$} & 11 & Status & $2.3(0-10)$ & $0.69(0.23-0.93)$ & $1.4(0-4)$ & $0.58(-0.06-0.96)$ & $8.2(1-60)$ & $0.84(0.56-0.99)$ & $12.8(3-25)$ & $0.52(0.00-.91)$ \\
\hline & 11 & Change & $-0.2(-1-1)$ & NA & $-0.2(-3-1)$ & $0.50(0.10-0.87)$ & $-0.35(-3-1)$ & NA & $-1.8(-17-10)$ & $0.50(-0.05-0.89)$ \\
\hline \multirow{2}{*}{$\begin{array}{l}\text { Exercise } 3 \\
3 \text { readers }\end{array}$} & 11 & Status & $1.8(0-10)$ & $0.63(0.46-0.93)$ & $1.7(0-5)$ & $0.60(0.34-0.80)$ & $6.6(0-65)$ & $0.88(0.77-0.94)$ & $12.8(2-28)$ & $0.89(0.87-0.91)$ \\
\hline & 11 & Change & $-0.12(-1-1)$ & NA & $-0.12(-3-2)$ & $0.60(0.48-0.83)$ & $-0.7(-7-0)$ & NA & $-1.6(-21-8)$ & $0.78(0.70-0.87)$ \\
\hline \multirow{4}{*}{$\begin{array}{l}\text { Exercise } 4 \\
9 \text { readers }\end{array}$} & $10(1-10)$ & Status & $1.2(0-4)$ & $0.21(-0.39-0.91)$ & $1.1(0-2)$ & $0.19(-0.31-0.69)$ & $1.8(0-6)$ & $0.07(-0.17-0.83)$ & $16.4(9-23)$ & $0.31(0.00-0.89)$ \\
\hline & $10(11-20)$ & Status & $1.6(0-6)$ & $0.51(-0.08-0.99)$ & $1(0-3)$ & $0.40(-0.17-0.88)$ & $3.5(1-8)$ & $0,08(-0.21-0.95)$ & $11.2(5-24)$ & $0.49(0.00-0.94)$ \\
\hline & $1011-20)$ & Change & $-0.4(-2-0)$ & NA & $-0.39(-2-0)$ & $0.22(-0.68-0.83)$ & $-2.2(-7-2)$ & NA & $-5.2(-18-0)$ & $0.57(0.02-0.92)$ \\
\hline & $20(1-20)$ & Status & $1.4(0-6)$ & $0.41(-0.35-0.92)$ & $1.0(0-3)$ & $0.27(-0.07-0.75)$ & $2.7(0-9)$ & $0.09(-0.17-0.85)$ & $13.8(5-25)$ & $0.45(0.01-0.90)$ \\
\hline \multirow{4}{*}{$\begin{array}{l}\text { Exercise } 4 \\
3 \text { readers }\end{array}$} & $10(1-10)$ & Status & $0.8(0-4)$ & $0.29(0.01-0.78)$ & $1.3(0-2)$ & $-0.02(-0.29-0.12)$ & $0.4(0-2)$ & $-0.04(-0.04-0.04)$ & $15.8(5-26)$ & $0.73(0.59-0.89)$ \\
\hline & $10(11-20)$ & Status & $1.8(0-9)$ & $0.65(0.52-0.76)$ & $1.2(0-4)$ & $0.72(0.62-0.81)$ & $1.7(0-5)$ & $0.06(-0.17-0.35)$ & $9.2(2-26)$ & $0.68(0.53-0.88)$ \\
\hline & $10(11-20)$ & Change & $-0.6(-2-0)$ & NA & $-0.5(-3-1)$ & $0.52(0.49-0.55)$ & $-0.2(-2-1)$ & NA & $-2.8(-19-6)$ & $0.85(0.82-0.88)$ \\
\hline & $20(1-20)$ & Status & $1.3(0-9)$ & $0.58(0.43-0.69)$ & $1.2(0-4)$ & $0.38(0.31-0.44)$ & $1.0(0-5)$ & $0.10(-0.09-0.33)$ & $12.5(2-26)$ & $0.73(0.69-0.77)$ \\
\hline
\end{tabular}

Sum scores and ICCs are mean (range). ICC is 2-way mixed, single measure, by absolute agreement.

Edmonton, Alberta, Canada; ${ }^{4}$ Medical Imaging Consultants, Edmonton, Alberta, Canada; ${ }^{5}$ University of Alberta, Department of Medicine, Edmonton, Alberta, Canada; ${ }^{6}$ CARE Arthritis, Edmonton, Alberta, Canada; ${ }^{7}$ Tel-Aviv University, Department of Diagnostic Imaging, Sheba Medical Center, Affiliated to the Sackler School of Medicine, Israel; ${ }^{8}$ University of New South Wales, Division of Medicine, Sydney, Australia; ${ }^{9}$ Université catholique de Louvain, Department of Rheumatology, Cliniques Universitaires Saint-Luc, Institut de Recherche Expérimentale et Clinique, Brussels, Belgium; ${ }^{10}$ Sorbonne University, Department of Rheumatology, APHP, Pitié-Salpêtrière Hospital, Paris, France ${ }^{11}$ University of Leeds, Leeds Institute of Rheumatic and Musculoskeletal Medicine, Leeds, United Kingdom; ${ }^{12}$ Leeds Teaching Hospitals NHS Trust, NIHR Leeds Biomedical Research Centre, Leeds, United Kingdom; ${ }^{13}$ Ghent University Hospital, Department of Rheumatology, Ghent, Belgium; ${ }^{14}$ Ghent University, VIB Inflammation Research Centre, Ghent, Belgium

Background: Whole-body MRI (WB-MRI) allows assessment of the overall inflammation in arthritis patients, including joint and entheses. To enhance the use of WB-MRI in clinical trials, the OMERACT MRI in Arthritis Working Group developed the OMERACT MRI Whole-body score for Inflammation in Peripheral joints and Entheses in inflammatory arthritis (MRI-WIPE) [1]. This has been validated for the entire body, including the hip/pelvis region, but not for each individual region. More detailed scoring systems exist for heels, hands and feet but although hip arthritis is a key cause of functional impairment in spondyloarthritis (SpA), no detailed scoring system has been published for use in SpA. The Hip Inflammation Magnetic Resonance Imaging Scoring System (HIMRISS) was developed and validated in osteoarthritis showing good reliability. Objectives: To validate reliability, correlation and responsiveness of two WB-MRI scores for the hip/pelvis region in $\mathrm{SpA}$.

Methods: Inflammation in the hip/pelvis region was assessed on coronal WB-MRIs in 4 iterative multi-reader exercises using MRI-WIPE for the hip/pelvis

\section{Figure 1}
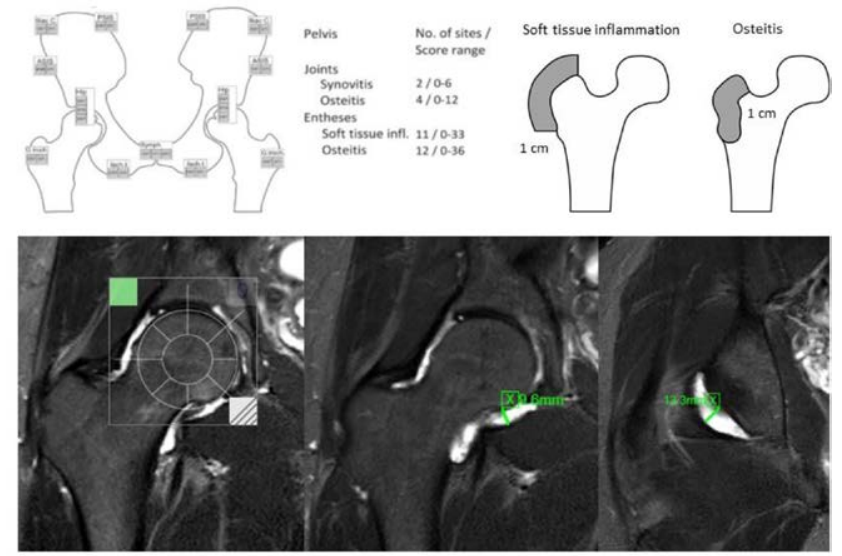

Figure 1. Upper row, left MRI-WIPE schematic and scoring ranges for the hip and pelvis insertion of the region from Krabbe et al [1]; Lower row, right schematic drawing of the principle of scoring ostetitis and soft tissue inflammation using MRI-WIPE, illustrated by
greater trochanter. Lower row: Left coronal STIR whole-body MR image of the hip with the web-based senirtransparent overlay used in HIMRISS for
ostetis scoring positioned for femoral head and acetabulum; Right two examples of synovitis effusion measuring according to HIMRISS. region and HIMRISS (Figure 1). In final exercises, images (axial/peripheral SpA and psoriatic arthritis) were obtained before and after TNF-inhibitor.

Results: In final exercises reliability was mostly good for the best calibrated readers. Median single-measure intraclass correlation coefficients were $0.58-0.65$ (WIPE osteitis), 0.10-0.88 (HIMRISS osteitis), 0.38-0.72/0.52-0.60 (WIPE synovitis/effusion) and 0.68-0.89/0.78-0.85 (HIMRISS synovitis/effusion) (Table 1). The methods correlated significantly for status in osteitis $(0.72, p=0.019)$ and for synovitis/effusion status $(0.83, p=0.003)$ and change $(0.73, p=0.017)$ (Table 1$)$. In exercise 4 Wilcoxon signed-rank test showed significant change in osteitis between timepoints using WIPE hip/pelvis and SRM was large (1.23), while lower for WIPE synovitis/effusion and HIMRISS.

Conclusion: MRI-WIPE and HIMRISS may be useful tools in modular WB-MRI evaluation of hip/pelvis inflammation in clinical trials in SpA. REFERENCES:

[1] Krabbe S et al. J Rheum. 2019;46(9):1215-21

[2] Jaremko JL et al. J Rheum. 2019;46(9)1239-42

Acknowledgements: We thank CARE Arthritis Limited (carearthritis.com) for help with setting up the web-based scoring interface, scoring exercises, and the web-based meetings. We acknowledge the contribution of SIG (Special Interest Group) participants at the virtual OMERACT meeting October 29, 2020. HMO, GDM and PGC are supported in part by the National Institute for Health Research (NIHR) Leeds Biomedical Research Centre, United Kingdom. The views expressed are those of the authors and not necessarily those of the NHS, the NIHR or the Department of Health.

Disclosure of Interests: Marie Wetterslev: None declared, Robert G Lambert Consultant of: Parexel and Pfizer, Walter P Maksymowych Speakers bureau: AbbVie, Janssen, Novartis, Pfizer and UCB, Consultant of: AbbVie, Boehringer Ingelheim, Celgene, Eli Lilly, Galapagos, Janssen, Novartis, Pfizer and UCB, Grant/research support from: AbbVie, Novartis, Pfizer and UCB, Iris Eshed: None declared, Susanne Juhl Pedersen Speakers bureau: MSD, Pfizer, AbbVie, Novartis and UCB, Consultant of: AbbVie and Novartis, Grant/research support from: AbbVie, MSD, and Novartis, Paul Bird Speakers bureau: Janssen, Abbvie, UCB, Celgene, BMS, Novartis, Pfizer, Gilead, Eli-Lilly, Consultant of: Janssen, Abbvie, UCB, Celgene, BMS, Novartis, Pfizer, Gilead, Eli-Lilly, Maria Stoenoiu: None declared, Simon Krabbe: None declared, Ashish Jacob Mathew: None declared, Violaine Foltz: None declared, Frederique Gandjbakhch: None declared, Joel Paschke: None declared, Gabriele De Marco: None declared, Helena Marzo-Ortega Speakers bureau: AbbVie, Celgene, Janssen, Lilly, Novartis, Pfizer, Takeda and UCB, Grant/research support from: Janssen and Novartis, Philippe Carron Speakers bureau: Pfizer, MSD, Novartis, BMS, AbbVie, UCB, Eli Lilly, Gilead and Celgene, Consultant of: Pfizer, MSD, Novartis, BMS, AbbVie, UCB, Eli Lilly, Gilead and Celgene, Grant/research support from: UCB, MSD and Pfizer, Anna Enevold Fløistrup Poulsen: None declared, Jacob L Jaremko: None declared, Philip G Conaghan Speakers bureau: AbbVie, BMS, Eli Lilly, Flexion Therapeutics, Galapagos, Gilead, Novartis, Pfizer, Regeneron, Stryker, Consultant of: AbbVie, BMS, Eli Lilly, Flexion Therapeutics, Galapagos, Gilead, Novartis, Pfizer, Regeneron, Stryker, Mikkel Østergaard Speakers bureau: Abbvie, BMS, Boehringer-Ingelheim, Celgene, Eli-Lilly, Hospira, Janssen, Merck, Novartis, Pfizer, Regeneron, Roche, Sandoz, Sanofi and UCB, Consultant of: Abbvie, BMS, Boehringer-Ingelheim, Celgene, Eli-Lilly, Hospira, Janssen, Merck, Novartis, Pfizer, Regeneron, Roche, Sandoz, Sanofi and UCB, Grant/research support from: Abbvie, BMS, Boehringer-Ingelheim, Celgene, Eli-Lilly, Hospira, Janssen, Merck, Novartis, Pfizer, Regeneron, Roche, Sandoz, Sanofi and UCB DOI: 10.1136/annrheumdis-2021-eular.952 